\title{
Relationship between socio-demographic and clinical variables, and health-related quality of life in patients with inflammatory bowel disease
}

\author{
B. López Blanco, B. Moreno-Jiménez, J. M. Devesa Múgica ${ }^{1}$ and A. Rodríguez Muñoz \\ Department of Basic Psychology and Health. Universidad Autónoma de Madrid. 'Unit of Coloproctology. Hospital \\ Universitario Ramón y Cajal. Madrid, Spain
}

\begin{abstract}
Objective: the principal aim of the present study is to evaluate the influence of socio-demographic and clinical variables on health-related quality of life (HRQL) in patients with inflammatory bowel disease.

Patients and method: this was a cross-sectional study. health-related quality of life was measured with the Inflammatory Bowel Disease Questionnaire (IBDQ). A total of 120 patients, 60 with ulcerative colitis and 60 with Crohn's disease, participated in the study.

Results: no significant differences were observed between ulcerative colitis and Crohn's disease patients in IBDQ dimensions. However, a multivariate analysis revealed that sex, type of treatment, extraintestinal symptoms, number of relapses in previous year, satisfaction with surgery, and need for psychological support were related to HRQL.

Conclusions: the identification of these variables associated with HRQL in patients with inflammatory bowel disease shows them to be basically non-disease factors. Knowledge of such elements can turn out to be very useful in order to guide future research and modify specific factors in further interventions.
\end{abstract}

Key words: Inflammatory bowel disease. Health-related quality of life. Sociodemographic and clinical variables.

López Blanco B, Moreno-Jiménez B, Devesa Múgica JM, Rodríguez Muñoz A. Relationship between socio-demographic and clinical variables, and health-related quality of life in patients with inflammatory bowel disease. Rev Esp Enferm Dig 2005; 97: 887-898.

\section{Recibido: 31-05-05.}

Aceptado: 06-09-05.

Correspondencia: Bernardo Moreno Jiménez. Departamento de Psicología Biológica y de la Salud. Facultad de Psicología. Universidad Autónoma de Madrid. Ctra. Colmenar Viejo, km. 15, 28049 Madrid. Fax: 914975215. e-mail. bernardo.moreno@uam.es

\section{INTRODUCTION}

Inflammatory bowel disease (IBD) consists of a group of chronic bowel disorders, including Crohn's disease (CD) and ulcerative colitis (UC), both characterized by alternating periods of remission with relapses (1). Thus, IBD can be considered a chronic disease highly associated with health-related quality of life (HRQL).

Although the etiology of IBD is unknown (2), the most widespread hypothesis suggests that it results from a multifactorial etiopatogenic mechanism in which family or genetic, infectious, immune, environmental, and psychological factors take part (3). The measurement of HRQL provides important data to quantify the impact of disease on the daily life of patients with IBD.

Although the influence of socio-demographic variables on the perception of HRQL seems to be limited in minor diseases (4), in chronic diseases such as IBD selected socio-demographic and clinical factors directly affect the development of the disease and the perception of HRQL. Some studies indicate that, in IBD, socio-demographic variables such as sex, age, or educational level directly affect HRQL (5-7). Clinical variables such as type of treatment (medical treatment or surgery), therapy effectiveness, the occurrence of extraintestinal symptoms, annual rate of flare-ups, their severity, or the need for hospitalization have an impact on IBD patients' HRQL (8). While there is some controversy in the field, it seems that patients with CD are more affected by their disease in terms of HRQL than are patients with UC (9-11). Identifying the factors associated with HRQL is relevant because, in the same cases, it may allow us to modify some of them, improving patients' health. Furthermore, the study of HRQL offers other advantages, especially, and as other studies $(4,7)$ have indicated, because of its medical and social implications, and the distribution of health resources. 
Despite the above-mentioned studies, there is some controversy over which variables have more impact on HRQL. The aim of the present study is to contribute to the analysis of the influence of several socio-demographic and clinical variables in IBD patients by means of a multivariate analysis in which the aforementioned variables are included.

\section{METHODS}

\section{Patients}

A cross-sectional study was carried out in 120 patients from two large centers for these diseases in the Community of Madrid. All participants were patients receiving outpatient treatment, and were diagnosed with CD or UC according to clinical, radiological, endoscopic, and anatomopathological criteria. By means of the clinical files, it was determined that none of the patients had any psychiatric condition; patients who had depression as a consequence of their disease were also excluded. All patients were under 75 years of age. In the initial design of the study, we tried to obtain homogeneous groups by matching our sample in terms of disease and type of treatment. Thus, the total sample comprised 30 patients with $\mathrm{CD}$ and medical treatment, 30 with $\mathrm{CD}$ and surgical treatment, 30 with UC and medical treatment, and 30 with UC and surgical treatment. Once a physician had confirmed the diagnosis and clinical history of IBD, the patients were informed about the goal of the research and asked to collaborate in the study, following the pertinent ethical recommendations and after obtaining their informed consent. The assessment instruments used were administered by a specialist trained in their use.

\section{Study variables}

Socio-demographic and clinical data were collected: sex, age, educational level, marital status, diagnosis, treatment, disease duration, number of relapses per year, need for hospitalization, family history of disease, satisfaction with surgery, extraintestinal symptoms, amount of information received from healthcare staff, and need for psychological support.

\section{Health-related quality of life}

HRQL was assessed using the Inflammatory Bowel Disease Questionnaire (IBDQ) (12), which is the most extensively used instrument to assess HRQL in these diseases. This scale has been shown to have satisfactory psychometric properties in former studies $(13,14)$. It consists of 32 questions grouped into four dimensions: bowel symptoms (10 items), systemic symptoms (5 items), so- cial functioning (5 items), and emotional functioning (12 items). Responses to each item are scored on a 7-point Likert scale, where 7 correspond to the highest level of function and 1 to the lowest. A 36-item version of the IBDQ, with five dimensions, has subsequently been developed. This latter version has been adapted and validated with regard to the Spanish population (15).

\section{Statistical analysis}

All analyses were carried out using the SPSS statistical package, version 11.5. First, a descriptive analysis of clinical and socio-demographic variables was conducted using chi-square and Student's t -test on categorical and constant variables, respectively. To explore the relationship between HRQL and the patients' socio-demographic and clinical characteristics, Student's t test was used for dichotomic variables, an analysis of variance (ANOVA) and Scheffé's test for categorical variables, and Pearson's correlation coefficient for constant variables. Subsequently, a multivariate analysis (MANOVA) was performed using each of the HRQL dimensions as dependent variables, with the socio-demographic and clinical variables that reached significance in the first univariate analysis as independent variables. A level of 0.05 was considered statistically significant.

\section{RESULTS}

\section{Sample description}

The patients' socio-demographic and clinical characteristics, as a function of type of disease, are summarized in table I.

Of the total sample, 64 were men $(53 \%)$ and 56 were women (47\%), with more women in the CD group of patients. Mean age was similar in both groups. Mean disease duration was also similar in both groups, with no significant differences. As regards smoking, significant differences were found: most of the patients with UC were nonsmokers, whereas a high percentage $(69 \%)$ of $\mathrm{CD}$ patients were active smokers $(\mathrm{p}<0.01)$. No significant differences in extraintestinal symptoms as suffered by the groups were found, with both groups having a similar number of dermatological, ophthalmic, and osteoarthropathic symptoms. The number of relapses in the previous year also showed a similar pattern: although patients with CD had a slightly higher mean, the difference was not significant, regardless of the need for hospitalization. Educational level was similar for both groups, with secondary education predominating among patients with $\mathrm{UC}$ and primary education among patients with $\mathrm{CD}$. Of the patients who underwent surgery, those from the $C D$ group were more satisfied with the intervention than patients with UC (83vs. 67\%), albeit without reaching sig- 
Table I. Description of sociodemographic and clinical characteristics as a function of type of disease

\begin{tabular}{|c|c|c|c|}
\hline Sociodemographic and clinical characteristics & $\begin{array}{l}\text { Crohn's disease } \\
\quad(n=60)\end{array}$ & $\begin{array}{l}\text { Ulcerative colitis } \\
\qquad(n=60)\end{array}$ & $\begin{array}{l}\text { Total sample } \\
\quad(n=120)\end{array}$ \\
\hline Sex: $n$ (\% females) & $31(52 \%)$ & $25(42 \%)$ & $56(47 \%)$ \\
\hline Mean age, $\pm S D$ (range) & $42 \pm 15(18-75)$ & $45 \pm 11(29-68)$ & $43 \pm 13(18-75)$ \\
\hline Smoker* $n(\%)$ & $41(69 \%)$ & $11(31 \%)$ & $55(46 \%)$ \\
\hline Extraintestinal symptoms $n(\%)$ & $21(35 \%)$ & $25(42 \%)$ & $46(38 \%)$ \\
\hline Mean number of relapses per year (range) & $1.02(0-5)$ & $0.72(0-3)$ & $0.87(0-5)$ \\
\hline \multicolumn{4}{|l|}{ Educational level: } \\
\hline Primary $n(\%)$ & $27(45 \%)$ & $19(28 \%)$ & $46(33 \%)$ \\
\hline Secondary $n(\%)$ & $20(33 \%)$ & $34(58 \%)$ & $54(49 \%)$ \\
\hline University $n(\%)$ & $13(22 \%)$ & $7(14 \%)$ & $20(18 \%)$ \\
\hline
\end{tabular}

${ }^{*} p<0.01$

nificance. As regards the need for psychological support as a result of the suffering from the disease, no significant differences were observed (33 and $38 \%$ of the patients required such support in the CD and UC groups, respectively).

\section{Variables affecting HRQL}

The scores in each of the IBDQ dimensions as a function of socio-demographic and clinical characteristics can be seen in table II.

Table II. Means of IBDQ dimensions as a function of sociodemographic and clinical characteristics in the univariate analysis

\begin{tabular}{|c|c|c|c|c|c|}
\hline & $\begin{array}{c}\text { Bowel } \\
\text { symptoms }\end{array}$ & $\begin{array}{l}\text { Systemic } \\
\text { symptoms }\end{array}$ & $\begin{array}{l}\text { Emotional } \\
\text { functioning }\end{array}$ & $\begin{array}{c}\text { Social } \\
\text { functioning }\end{array}$ & $\begin{array}{l}\text { Global IDBQ } \\
\text { score }\end{array}$ \\
\hline \multicolumn{6}{|l|}{ Gender } \\
\hline Male & $58.67(0.022)$ & $29.23(0.002)$ & $68.60(0.005)$ & $31.17(0.020)$ & $189.78(0.010)$ \\
\hline \multicolumn{6}{|l|}{ Diagnosis } \\
\hline UC & 56.47 & 28.43 & 68.35 & 29.88 & 183.13 \\
\hline$C D$ & 56.28 & 26.52 & 64.57 & 29.72 & 177.09 \\
\hline Surgical & 52.12 & 25.60 & 64.08 & 28.12 & 169.91 \\
\hline \multicolumn{6}{|l|}{ Smoker } \\
\hline Yes & $53.00(0.044)$ & $25.40(0.030)$ & 63.29 & 29.51 & 171.20 \\
\hline No & 57.76 & 28.33 & 67.76 & 29.92 & 183.77 \\
\hline \multicolumn{6}{|c|}{ Extraintestinal manifestations } \\
\hline Yes & $54.18(0.009)$ & $25.74(0.000)$ & $63.03(0.001)$ & 29.22 & $172.17(0.010)$ \\
\hline \multicolumn{6}{|l|}{ Familiar history } \\
\hline Yes & 58.13 & 26.88 & 70.38 & 27.50 & 182.88 \\
\hline No & 56.25 & 27.52 & 66.18 & 29.96 & 179.91 \\
\hline \multicolumn{6}{|l|}{ Educational level } \\
\hline Primary & 54.33 & 26.78 & 65.10 & 29.78 & 175.99 \\
\hline Secondary & 54.71 & 27.11 & 66.49 & 28.37 & 176.68 \\
\hline Superiors & 61.08 & 26.83 & 64.92 & 29.42 & 182.25 \\
\hline \multicolumn{6}{|c|}{ Satisfaction with surgical intervention } \\
\hline Yes & 53.53 & 26.60 & 66.27 & $29.56(0.011)$ & $175.95(0.035)$ \\
\hline No & 47.87 & 22.60 & 57.53 & 23.80 & 151.80 \\
\hline \multicolumn{6}{|c|}{ Need of psychological support } \\
\hline Yes & 57.79 & 26.88 & $58.30(0.000)$ & $27.05(0.010)$ & $170.02(0.030)$ \\
\hline
\end{tabular}

Note. Variables with statistically significant differences appear with significance level (p) in brackets. 
In the univariate analysis, men had higher HRQL scores than did women in all the dimensions of the questionnaire, with especially significant differences in the emotional dimension $(p=0.005)$. Another variable that, in the initial analysis, turned out to be significant was the type of treatment received by the patient. Patients undergoing surgery had lower HRQL scores in all dimensions, reaching statistical significance in bowel symptoms $(\mathrm{p}=$ $0.000)$, systemic symptoms $(\mathrm{p}=0.002)$, and social functioning $(\mathrm{p}=0.008)$. Among smokers, lower scores in bowel $(p=0.044)$ and systemic symptoms $(p=0.030)$ were observed. Patients with extraintestinal symptoms had lower HRQL scores in the dimensions of bowel symptoms $(p=0.009)$, systemic symptoms $(p=0.000)$, and emotional functioning $(\mathrm{p}=0.001)$. Regarding satisfaction with surgery, patients who were satisfied with the result of the intervention obtained significantly higher scores in social functioning $(\mathrm{p}=0.011)$ and overall IBDQ score $(p=0.035)$. Conversely, patients who expressed the need for psychological support obtained lower scores in the emotional $(\mathrm{p}=0.000)$ and social dimensions $(\mathrm{p}=$ $0.010)$, and in the overall IBDQ score $(p=0.030)$.

As can be seen in table III, the results of the multivariate analysis showed that only type of treatment (medical $v s$. surgical) remained significant in all dimensions, except for emotional functioning, where patients who had undergone surgery obtained lower HRQL scores (Fig. 1A). In contrast, sex had significant effects on systemic symptoms $(\mathrm{p}=0.048)$ and emotional functioning $(\mathrm{p}=$ 0.009 ). Scores in these dimensions were significantly lower in women (Fig. 1B). Similarly, extraintestinal symptoms had a significant effect on systemic symptoms $(\mathrm{p}=0.016)$ and emotional functioning $(\mathrm{p}=0.043)$. Satisfaction with surgery had a significant effect on the IBDQ dimension of social functioning $(\mathrm{p}=0.018)$. The need for psychological support also maintained its significance in the dimensions of emotional $(p=0.002)$ and social functioning $(\mathrm{p}=0.025)$ (Fig. 1C).

Table III. $\boldsymbol{F}$ values and significance of sociodemographic and clinical variables for IDBQ dimensions in the multivariate analysis

\begin{tabular}{lll}
\hline & $F$ & $p$ \\
\hline Sex & & \\
$\quad$ Bowel symptoms & 1.388 & 0.224 \\
Systemic symptoms & 2.609 & $0.048^{*}$ \\
Emotional functioning & 3.733 & $0.009^{*}$ \\
Social functioning & 1.618 & 0.193 \\
Global IBDQ score & 2.106 & 0.150 \\
& & \\
Treatment & & \\
Bowel symptoms & 4.117 & $0.007^{*}$ \\
Systemic symptoms & 2.981 & $0.018^{*}$ \\
Emotional functioning & 1.089 & 0.135 \\
Social functioning & 2.126 & $0.035^{*}$ \\
Global IBDQ score & 3.924 & $0.050^{\star}$
\end{tabular}

Table III. $F$ values and significance of sociodemographic and clinical variables for IDBQ dimensions in the multivariate analysis (continuation)

\begin{tabular}{|c|c|c|}
\hline & $F$ & $p$ \\
\hline \multicolumn{3}{|l|}{ Extraintestinal symptoms } \\
\hline Bowel symptoms & 2.770 & 0.102 \\
\hline Systemic symptoms & 5.648 & $0.016 *$ \\
\hline Emotional functioning & 4.587 & $0.043^{*}$ \\
\hline Social functioning & 1.525 & 0.272 \\
\hline Global IBDQ score & 1.238 & 0.150 \\
\hline \multicolumn{3}{|l|}{ Smoker } \\
\hline Bowel symptoms & 1.704 & 0.197 \\
\hline Systemic symptoms & 2.364 & 0.112 \\
\hline Emotional functioning & 0.375 & 0.543 \\
\hline Social functioning & 0.407 & 0.521 \\
\hline Global IBDQ score & 1.954 & 0.175 \\
\hline \multicolumn{3}{|l|}{ Satisfaction with surgery } \\
\hline Bowel symptoms & 2.049 & 0.158 \\
\hline Systemic symptoms & 2.769 & 0.102 \\
\hline Emotional functioning & 2.604 & 0.089 \\
\hline Social functioning & 5.920 & $0.018^{*}$ \\
\hline Global IBDQ score & 2.256 & 0.105 \\
\hline \multicolumn{3}{|c|}{ Need for psychological support } \\
\hline Bowel symptoms & 1.677 & 0.189 \\
\hline Systemic symptoms & 1.081 & 0.215 \\
\hline Emotional functioning & 6.494 & $0.002 * *$ \\
\hline Social functioning & 4.189 & $0.025^{\star}$ \\
\hline Global IBDQ score & 2.124 & 0.110 \\
\hline
\end{tabular}

To analyze the relationship between continuous variables and IBDQ dimensions, a Pearson correlation analysis was carried out. The results are displayed in table IV.

The number of relapses suffered by the patients during the previous year is related to the dimensions in IBDQ. The need for hospitalization seems important, as it shows significant correlations with all IBDQ dimensions and with its global score.

\section{DISCUSSION}

In spite of several studies carried out, there are still doubts about which variables have more influence on HRQL in patients with IBD. The results of the present study, in accordance with previous researches $(4,16)$, confirm that several socio-demographic (sex) and clinical characteristics (type of treatment, extraintestinal symptoms, number of relapses per year, satisfaction with surgery, and need for psychological support) significantly affect HRQL in IBD patients. There is some controversy about whether there are HRQL differences in UC and CD patients. In our study, HRQL was not influenced by diagnosis, as significant differences between $\mathrm{UC}$ and $\mathrm{CD}$ patients in IBDQ dimensions were not found. The present results are in line with findings of the study by Casellas et 


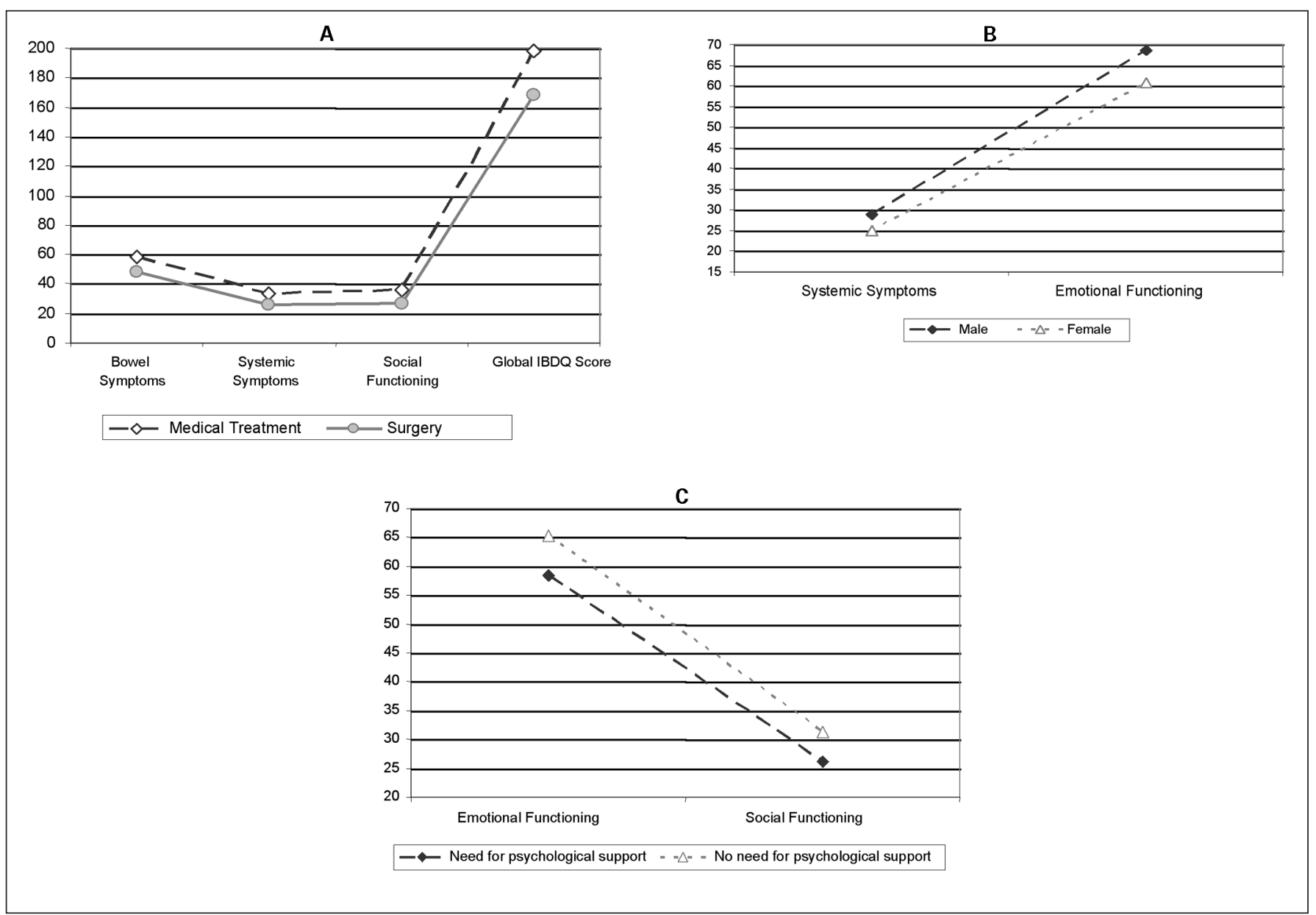

Fig. 1.- A: HRQL as a function of sex. B: HRQL as a function of type of treatment. C: HRQL as a function of need for psychological support. A: CVRS en función del sexo. B: CVRS en función del tipo de tratamiento. C: CVRS en función de la necesidad de apoyo psicológico.

Table IV. Correlations between demographic and clinical variables, and IBDQ dimensions

\begin{tabular}{|c|c|c|c|c|c|}
\hline Age & 0.058 & 0.156 & 0.149 & 0.120 & 0.125 \\
\hline No. of relapses requiring hospitalization & $-0.256 * *$ & $-0.354^{* *}$ & $-0.351 * *$ & $-0.374 * *$ & $-0.369 * *$ \\
\hline No. of relapses not requiring hospitalization & $-0.266 * *$ & $-201 *$ & -0.133 & $-0.218^{*}$ & $-0.238 * *$ \\
\hline
\end{tabular}

${ }^{*} p<0.05 ;{ }^{* *} p<0.01$.

al. (17), in which IBDQ scores were similar for both diseases. In one of the studies of HRQL in IBD patients, it was found that diagnosis did not influence any of the IBDQ dimensions (18), although other studies show that CD patients have a poorer HRQL when compared to UC patients.

As in the study by Casellas et al. (4), factors associated with disease severity, such as number of relapses or type of treatment, were strongly related to HRQL. In the present study, patients who had undergone surgery had a poorer HRQL versus those who had received medical treatment exclusively. These data are in contrast with the findings by Casellas et al. (8), who, in a sample of IBDQ patients, found that HRQL was not affected by type of treatment. One of the variables associated with treatment, satisfaction with surgery, has been shown to affect patient emotional functioning. In contrast to previous research (19), another factor that has been identified to influence HRQL is the number of relapses during the previous year. Number of relapses correlated negatively with IBDQ scores. Although the present sample consisted of outpatients, we were also interested in observing the impact of 
the need for hospitalization, as it affects HRQL negatively (4). Thus, a differentiation between relapses with or without the need for hospitalization was made. In this sense, results indicate that if a relapse entailed the need for hospitalization, it had significantly more impact on HRQL. In contrast to previous studies (20), smoking did not affect HRQL (4). While in the univariate analysis smokers showed a poorer HRQL, this effect disappeared in the multivariate analysis.

Regarding the need for psychological support, this variable seems to influence HRQL in IBD patients, specifically in the emotional and social aspects. This finding is consistent with previous studies that indicate the relevance of some psychological variables, such as the expression of emotions $(21,22)$ or coping strategies (23) in the development of IBD.

Furthermore, results showed that some socio-demographic variables, such as sex, influence the perception of HRQL. Few studies have shown the effect of sex on the perception of HRQL in IBD patients, although our results tend to confirm that women obtain lower scores than men $(24,25)$. In our study, the results of the multivariate analysis showed that men scored higher in all IBDQ dimensions, with significant values in systemic symptoms and emotional functioning. This reverse relationship between women and HRQL has been found in other diseases such as rectum cancer (26). In the present study, the influence of other socio-demographic factors (age, educational level, and marital status) on the perception of HRQL was not significant. Traditionally, educational level was one of the factors associated with perception of HRQL in these patients $(6,27)$. In a study with a Spanish sample, patients with university-level education showed better HRQL scores than did patients with a primary educational level (28). Nevertheless, these data were not confirmed in our study.

To sum it all up, our results lead us to conclude that type of treatment, sex, extraintestinal symptoms, satisfaction with surgery, need for psychological support, and number of relapses during the previous year (with or without hospitalization) are associated with HRQL in the patients studied. The knowledge and identification of variables related to HRQL in IBD patients may prove very useful in the guidance of future research and the modification of specific factors in future interventions.

\section{ACKNOWLEDGEMENTS}

The authors wish to thank Hospital General Universitario Gregorio Marañón and Hospital Universitario Ramón y Cajal for their assistance in the recruitment of IBD patients. Thanks are also due to the Crohn's Disease and Ulcerative Colitis Patients' Association for their support in carrying out this study. We also thank participants themselves.

\section{REFERENCES}

1. Kamm M. Inflammatory bowel disease. London: Martin Dunitz, 1999.

2. Fiocchi C. Inflammatory bowel disease: etiology and pathogenesis. Gastroenterology 1998; 115: 182-205.

3. Glickamn M. Enfermedad inflamatoria intestinal: colitis ulcerosa y enfermedad de Crohn. In: Braunwald E, ed. Principios de Medicina interna. McGraw-Hill/Interamericana, 1998. p. 1853-68.

4. Casellas F, López Vivancos J, Casado A, Malagelada JR. Factors affecting health related quality of life of patients with inflammatory bowel disease. Qual Life Res 2002; 11: 775-81.

5. Han S.W. Relationship between quality of life, symptom activity and illness perception in patients with ulcerative colitis. Gastroenterology 1999; 116: A63.

6. Hjortswang H, Jarnerot G, Curman B, Sandberg-Gertzen C, Blomberg B, Almer S, et al. The influence of demographic and disease-related factors on health-related quality of life in patients with ulcerative colitis. Eur J Gastroenterol Hepatol 2003; 15: 1011-20.

7. Irvine EJ, Feagan B, Rochon J, Archambault A, Fedorak RN, Groll A, et al. Quality of life: a valid and reliable measure of therapeutic efficacy in the treatment of inflammatory bowel disease. Gastroenterology 1994; 106: 287-96.

8. Casellas F, López Vivancos J, Badia X, Vilaseca J, Malagelada JR. Impact of surgery for Crohn's disease on health-related quality of life. Am J Gastroenterol 2000; 95(1): 177-82.

9. Drossman D, Leserman J, Mitchell M, Zhiming M, Zagamin E, Patrick D. Health status and health care use in persons with inflammatory bowel disease: a national sample. Dig Dis Sci 1991; 36: 1746-55.

10. Farmer R, Easley K, Farmer J. Quality of life assessment by patients with inflammatory bowel disease. Cleve Clin J Med 1992; 59: 35-42.

11. Irvine E. Quality of life issues in patients with inflammatory bowel disease. Am J Gastroenterol 1997; 92: 18-24.

12. Guyatt G, Mitchell A, Irvine EJ, Singer J, Williams N, Goodacre R, et al. A new measure of health status for clinical trials in inflammatory bowel disease. Gastroenterology 1989; 96: 804-10.

13. Irvine EJ, Feagan B, Rochon J, Archambault A, Fedorak RN, Groll A, et al. Quality of life: a valid and reliable measure of therapeutic efficacy in the treatment of inflammatory bowel disease. Gastroenterology 1994; 106: 287-96.

14. Guyatt GH, Feeny DH, Patrick DL. Measuring health-related quality of life. Ann Intern Med 1993; 118: 622-9.

15. López Vivancos J, Casellas F, Badiac X, Vilaseca J, Malagelada JR. Validation of the Spanish version of the Inflammatory Bowel Disease Questionnaire on Ulcerative Colitis and Cohn's Disease. Digestion 1999; 60: 274-80.

16. Nordin K, Pahlman L, Larsson K, Sundberg-Hjelm M, Lööf L. Health-related quality of life and psychological distress in a populationbased sample of Swedish patients with inflammatory bowel disease. Scand J Gastroenterol 2002; 4: 450-7.

17. Casellas F, López-Vivancos J, Badia X, Vilaseca J, Malagelada JR. Influence of inflammatory bowel disease on different dimensions of quality of life. Eur J Gastroenterol Hepatol 2001; 13: 567-72.

18. Mitchell A, Guyatt G, Singer J, Irvine EJ, Goodacre R, Tompkins C, et al. Quality of life in patients with inflammatory bowel disease. J Clin Gastroenterol 1988; 10: 306-10.

19. Casellas F, López Vivancos J, Malagelada JR. Previous experience and quality of life in patients with inflammatory bowel disease during relapse. Rev Esp Enferm Dig 2003; 95 (7): 476-9.

20. Fraga XJ, Vergara M, Medina C, Casellas F, Bermejo B, Malagelada JR. Effects of smoking on the presentation and clinical course of inflammatory bowel disease. Eur J Gastroenterol Hepatol 1997; 9 (7): 683-7.

21. Vaughn C, Leff J, Sarner M. Relatives' expressed emotion and the course of inflammatory bowel disease. J Psychosom Res 1999; 47 (5): 461-9

22. Verissimo R, Mota-Cardoso R, Taylor G. Relationships between alexithymia, emotional control, and quality of life in patients with inflammatory bowel disease. Psychother Psychosom 1998; 67: 75-80.

23. Van der Zaag-Loonen HJ, Grootenhuis MA, Last BF, Derkx HH. Coping strategies and quality of life of adolescents with inflammatory bowel disease. Qual Life Res 2004; 13 (5): 1011-9. 
24. Anam S, Hanauer S. The effect of sex on quality of life instruments in inflammatory bowel disease. Gastroenterology 1998; 114: A919.

25. Irvine EJ, Greenberg GR, Feagan BG. Quality of life improves with budesonide therapy for active Crohn's disease. Inflammatory Bowel Dis 2000; 6: 181-7.

26. Pérez Lara FJ, Navarro Pinero A, de la Fuente Perucho A. Study of factors related to quality of life in patients with locally advanced rec- tal cancer. Rev Esp Enferm Dig 2004; 96 (11): 746-57.

27. Irvine EJ, Grace E, Kerr GD, Lyrenas E, Bolin T, O'Morain C, et al. Non-disease related factors affecting health related quality of life in inflammatory bowel disease. Gastroenterology 1998; 114: A1002.

28. Badia X, Fernández E, Segura A. Influence of socio-demographic and health status variables on evaluation of health states in a Spanish population. Eur J Publ Heath 1995; 5: 87-93. 